\title{
Influence of the Madden-Julian Oscillation on Southern African Summer Rainfall
}

\author{
B. POHL AND Y. RichaRD \\ Centre de Recherches de Climatologie, CNRS/Université de Bourgogne, Dijon, France \\ N. FAuchereau \\ Department of Oceanography, University of Cape Town, Rondebosch, South Africa
}

(Manuscript received 7 June 2006, in final form 13 November 2006)

\begin{abstract}
Composite maps of outgoing longwave radiation (OLR) anomalies over the Madden-Julian oscillation (MJO) cycle show marked intraseasonal fluctuations over southern Africa (south of $15^{\circ} \mathrm{S}$ ). Large-scale convective clusters are seen to propagate eastward and then northward over the continent, mainly between $10^{\circ}$ and $20^{\circ} \mathrm{S}$. The corresponding response of the rainfall field presents the alternation, over the cycle, of dry and humid phases, which are both significant. Moisture flux anomalies indicate an intraseasonal modulation of the midtropospheric easterly flow over the Congo basin at $700 \mathrm{hPa}$; these fluctuations are coupled to meridional flux anomalies that extend from the tropical to the subtropical austral latitudes, and favor occurrences of wet or dry conditions over the domain. Though statistically significant, the influence of the MJO on southern Africa is however not homogeneous spatially, and only the tropical areas exhibit sharp periodicities in the 30-60-day period range.

The OLR dipole observed in previous studies at the interannual and synoptic time scales between the hinterland parts of southern Africa and the southwestern Indian Ocean in the north of Madagascar is investigated next, as it also shows strong fluctuations at the intraseasonal time scale. The study points out that the dipole is partly influenced by the MJO, though the strongest periodicities are found for slightly longer periods (35-80 days) than those typically associated with the oscillation. The forcing of the MJO on the OLR dipole, though significant, remains thus partial.
\end{abstract}

\section{Introduction}

It has been established for decades that the MaddenJulian oscillation (MJO) is the dominant mode of intraseasonal variability in the tropical atmosphere (Madden and Julian 1994; Zhang 2005). It basically consists in a slow eastward propagation of large-scale convective clusters along the equator, from the Indian Ocean to the Maritime Continent and then to the western $\mathrm{Pa}$ cific basin. The time taken by the MJO to rejuvenate over the Indian Ocean is typically between 40 and 45 days, but more generally varies from 30 to 60 days. Therefore, it holds out the promise of significant medium-range predictability in the tropical atmosphere (Waliser et al. 1999; Waliser et al. 2003).

The MJO was shown to strongly interact with the

Corresponding author address: Benjamin Pohl, Centre de Recherches de Climatologie, Faculté des Sciences Gabriel, BP27877 F-21078, Dijon CEDEX, France.

E-mail: benjamin.pohl@u-bourgogne.fr
Indian (Yasunari 1979, 1980, 1981) and Australian (Hendon and Liebmann 1990a,b) monsoon systems. Over Africa the effects of the intraseasonal oscillation are not as well understood. Matthews (2004) showed that it significantly affects the West African monsoon. Mutai and Ward (2000) suggested that it is also implicated in the alteration of wet and dry phases during the rainy seasons over equatorial East Africa, which was confirmed by Pohl and Camberlin (2006). The effects of the intraseasonal oscillation over coastal and western Tanzania were more specifically discussed in Kijazi and Reason (2005) and Mapande and Reason (2005).

The location of southern Africa, between $15^{\circ}$ and $35^{\circ} \mathrm{S}$, interestingly questions to what extent the MJO is liable to imply intraseasonal fluctuations in the rainfall field. The subtropical part of the domain, located far away from the core regions of the $\mathrm{MJO}$, and showing strong interactions with the austral midlatitudes (Harrison 1984, 1986; Washington and Todd 1999), seems particularly important to focus on. Several recent studies, such as Goulet and Duvel (2000), Roundy and

DOI: $10.1175 / J C L I 4231.1$ 
Frank (2004), and Zhang and Dong (2004), indeed showed that the MJO tends to be preferentially located in the $10^{\circ}-15^{\circ}$ latitudes in the summer hemisphere. During austral summer, the oscillation also tends to show its most coherent signals, with a marked propagation of convective anomalies in the Eastern Hemisphere (Hendon et al. 1999).

However, following Makarau and Jury (1997) or Jury (1999), the MJO was not the primary process involved in intraseasonal convective fluctuations over the area. Several studies (Lyons 1991; Todd and Washington 1999; Washington and Todd 1999; Todd et al. 2004) pointed out that major rainfall fluctuations are for instance related to "tropical-temperate troughs" (TTTs) resulting from interactions between the tropical circulation and the midlatitude dynamics. These TTT systems are primarily observed at the synoptic scale, and thus on shorter time scales than those of the MJO. Nevertheless, Levey and Jury (1996) showed that the rainfall and evaporation fields also exhibit significantly longer periodicities, in the 30-60-day time range, which is indeed reminiscent of the MJO. More recently, an objective classification of large-scale atmospheric circulation anomalies over the western Indian Ocean region (Pohl et al. 2005) concured on significantly induced rainfall anomalies extending over the entire east coast of Africa, from Arabia to southern Africa; the MJO was particularly involved in the rain-causing processes.

In the present paper a quantification of the role of the MJO over southern Africa is proposed, using newer statistical approaches to capture the intraseasonal signal. Focus is thus on the intraseasonal variability of atmospheric convection and associated rainfall over southern Africa (south of $15^{\circ} \mathrm{S}$ ) during the summer period (October through April). Section 2 depicts the data and methodology used for this work. Section 3 documents the intraseasonal fluctuations in tropical convection over the region. Section 4 focuses on the rainfall response to the MJO-induced fluctuations. The results are then summarized and discussed in section 5 .

\section{Data and methods}

Rainfall amounts over Southern Africa are provided by the rain gauge records compiled in the South African Water Research Commission dataset (Lynch 2003). For the 1970-99 period, 7665 stations (out of $\sim 11000$ ), presenting no missing values, are extracted; they document the rainfall field over South Africa and the neighboring countries of Lesotho and Swaziland (Fig. 1). To extend the domain to the lower latitudes (Namibia, Botswana, Zimbabwe, and Mozambique), a second group of 72 stations was extracted, from only the 1970-

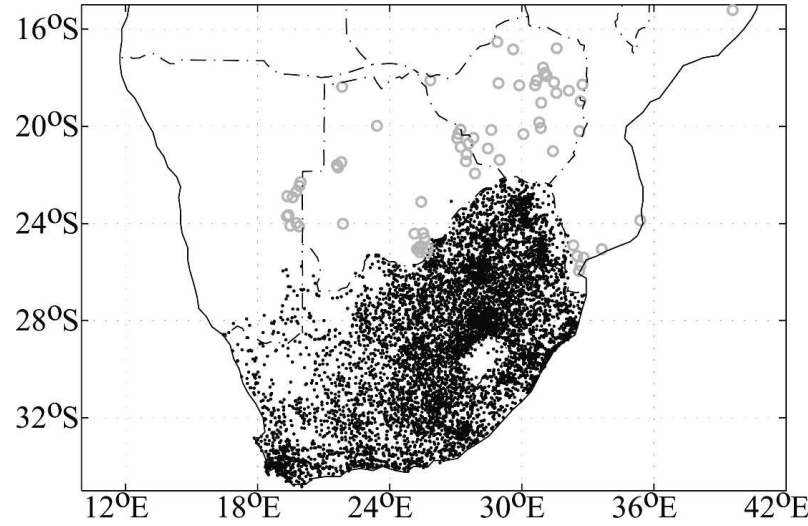

FIG. 1. Location of the rain gauge stations. The black points correspond to the 7665 subtropical stations, available for the 1970-99 period. The gray circles show the 72 additional tropical stations, available for $1970-89$.

89 period, for reasons of availability. For the latter, missing values were filled up using the surrounding values, by a 15-day moving average process with a minimum tolerance of at least 7 days informed. To allow comparison between the two groups of stations and to remove high-frequency noise, all rain gauge records were filtered using a Butterworth 10-day low-pass filter. The efficiency of this filtering technique was for instance discussed in Fink and Speth (1997). The use of such a low-pass filter is seen to have a very limited impact on the final results (not shown), and in particular on the significance of the intraseasonal fluctuations. The Climate Prediction Center (CPC) Merged Analysis of Precipitation (CMAP) dataset (Xie and Arkin 1997) provided additional rainfall estimates based on rain gauge and satellite measurements. It is available since 1979 at the pentad (5 day) time scale, on a $2.5^{\circ} \times 2.5^{\circ}$ regular grid.

Atmospheric dynamics are provided by the National Centers for Environmental Prediction-Department of Energy (NCEP-DOE) Atmospheric Model Intercomparison Project (AMIP-II) (NCEP-2) reanalyses (Kanamitsu et al. 2002). This study makes use of the zonal $(U)$ and meridional $(V)$ components of the wind $\left(\mathrm{m} \mathrm{s}^{-1}\right)$. Specific humidity $\left(Q, \mathrm{~g} \mathrm{~kg}^{-1}\right)$ was calculated from the relative humidity (rh, \%) and air temperature $(T, \mathrm{~K})$ using the Goff-Gratch equation (Goff and Gratch 1946). Moisture flux anomalies were derived from the fields $U, V$, and $Q$. Tropical convection was estimated using the daily version of the outgoing longwave radiation (OLR) dataset (Liebmann and Smith 1996). OLR is available for the period 1974-today, with a 10-month gap in 1978. Sea surface temperatures (SSTs) are obtained from the Hadley Centre Sea Ice and SST dataset (HadISST; Rayner et al. 2003); they 
are available at the monthly time scale on a $1^{\circ} \times 1^{\circ}$ regular grid, for the 1950-today period.

The intraseasonal oscillation was extracted using daily MJO indices following a methodology detailed in Wheeler and Hendon (2004), and also used in Matthews (2000) and Hsu and Lee (2005). They are based on a principal component analysis (PCA) applied on atmospheric fields known to significantly respond to the MJO. We chose here the 20-75-day filtered velocity potential deseasonalized anomalies at $200 \mathrm{hPa}\left(\chi_{200}\right)$ as it constitutes an accurate descriptor of the MJO (Knutson and Weickmann 1987). The filter was applied to remove other signals, among which were those associated with the El Niño-Southern Oscillation (ENSO). Here, $\chi_{200}$ is derived from the NCEP-National Center for Atmospheric Research (NCAR) reanalyses (Kalnay et al. 1996), for the 1970-99 period. The PCA is calculated on the tropical belt, between $20^{\circ} \mathrm{N}$ and $20^{\circ} \mathrm{S}$. The first two PCs, explaining $79 \%$ of the initial variance, are in quadrature, which makes it possible to use polar coordinates to characterize intraseasonal activity (Matthews 2000). A distance measurement quantifies the global amplitude of the oscillation, and an angle measurement indicates its phase, that is, the corresponding longitude of the MJO-associated convective clusters within the Tropics. The main interest is that each MJO cycle is strictly equal to $2 \pi \mathrm{rad}$, instead of varying temporally from 30 to 60 days. As similar extractions of the MJO are quite well known, the results of the PCA are not shown here.

To illustrate how the MJO indices can be used, the Hovmöller diagram in Fig. 2 depicts the mean eastward propagation of atmospheric convection along the equator during the austral summer season. The analysis is applied for October-April (ONDJFMA) 1974-99, the longest common period between the rainfall and OLR data; 1978 was excluded from the analysis. As an MJO cycle strictly corresponds to $2 \pi \mathrm{rad}$. It is noted that one-eighth of the cycle (i.e., $\Delta \pi / 4$ ) typically represents a 5-6-day period, in the case of a median period value made up of between 40 and 48 days.

MJO-associated convective clusters (negative OLR anomalies) are located over Africa between phase $7 \pi / 4$ and $\pi / 4$. Then they shift over the Indian Ocean (phases $\pi / 4$ to $\pi / 2$ ) where they exhibit their stronger convection anomalies, before dramatically decreasing over the western Pacific near the date line (phase $5 \pi / 4$ ). On the contrary, suppressed convection over Africa is centered on phase $\pi$. At this time of the cycle the MJO convection zonal dipole between the Indian (suppressed convection) and the Pacific (enhanced convection) domain is clearly observed. The symmetric situation is found at phase $2 \pi$.

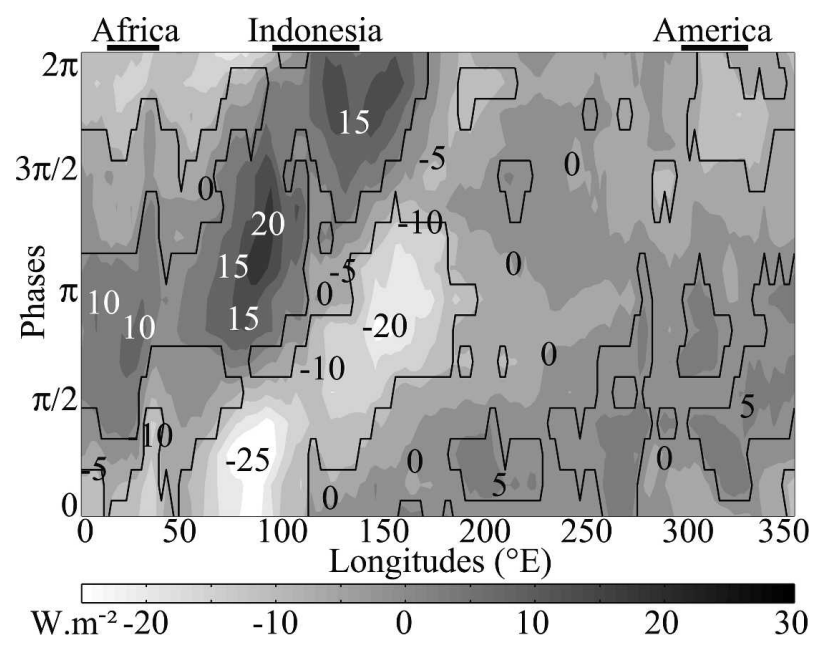

FIG. 2. Hovmöller diagram of composite OLR anomalies $\left(\mathrm{W} \mathrm{m}^{-2}\right)$ along the equator $\left(5^{\circ} \mathrm{N}-5^{\circ} \mathrm{S}\right)$ over the MJO cycle, after removal of the annual cycle. The period of analysis is October through April, from 1974 to 1999. Contour interval (CI) is $5 \mathrm{~W}$ $\mathrm{m}^{-2}$; see legend for shading. Solid black lines encompass anomalies that are significant at the $95 \%$ level according to a $t$ test.

During austral summer, OLR anomalies reach the $95 \%$ significance level over major parts of the tropical belt, even in the Western Hemisphere where the MJO is much weaker. The MJO-influenced areas also include equatorial Africa, as significant positive and negative OLR anomalies alternate over the cycle. The influence of the MJO on southern African convection is thus questionable; it is discussed in section 3.

\section{Intraseasonal convective activity over southern Africa}

\section{a. Mean fields}

To examine the amplitude of intraseasonal fluctuations of convection over the area, the standard deviation of the 20-75-day bandpass-filtered OLR $\left(\sigma_{\text {OLR }}\right)$ is first represented (Fig. 3). Such a filtering makes it possible to use OLR as a proxy for MJO activity (Hsu and Lee 2005). Note however that all other results concerning OLR are based on unfiltered values.

The extension area of the MJO during austral summer (Fig. 3), that is, the Indian and west Pacific basins, clearly appears as the area over which $\sigma_{\mathrm{OLR}}$ is the highest. The spatial pattern of $\sigma_{\mathrm{OLR}}$ is reminiscent of the location of the ITCZ at this time of the year (Waliser and Gautier 1993). Over the oceans, a very strong spatial consistency is indeed found between $\sigma_{\mathrm{OLR}}$ and the mean SST field during the season, the areas where SST is over the $27.5^{\circ} \mathrm{C}$ critical threshold (Graham and Barnett 1987) corresponding to the strongest OLR fluctua- 


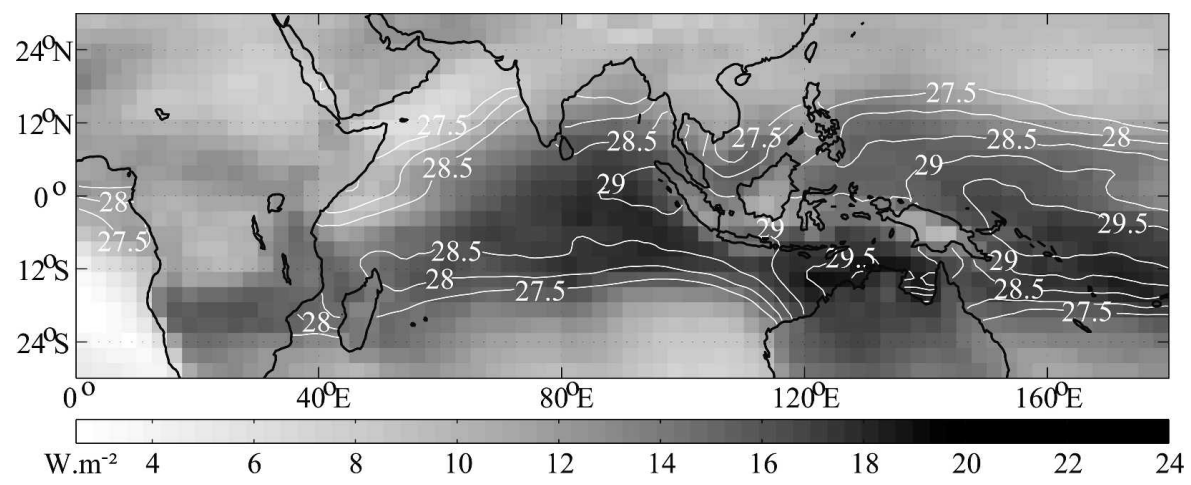

FIG. 3. Std dev of 20-75-day bandpass-filtered OLR grid points $\left(\mathrm{W} \mathrm{m}^{-2}\right)$, October-April 1974-99. See legend for shading. The white lines are isotherms that show the mean SST values over the $27.5^{\circ} \mathrm{C}$ critical threshold during the same period. $\mathrm{CI}$ is $0.5^{\circ} \mathrm{C}$.

tions at the intraseasonal time scale. Interestingly the OLR grid points over landmasses and oceans exhibit sharp contrasts, for example, over the Maritime Continent region, and intraseasonal convection is more strongly modulated by the MJO over the oceanic parts of the domain. Two exceptions are however noticeable: The main one corresponds to the Australian monsoon, significantly responding to the MJO (Hendon and Liebmann 1990b). The second one takes place over southern Africa $\left(14^{\circ}-22^{\circ} \mathrm{S}\right)$, denoting another potential forcing of the oscillation over the region. Over the continents, highest $\sigma_{\mathrm{OLR}}$ values thus correspond to the principal heat lows and associated convection areas (Angola low in southern Africa, Queensland, and Pilbara lows in Australia). Schematically, during Southern Hemisphere summer, MJO activity seems therefore to be located farther south over continental areas than over oceanic ones.

Composites of OLR anomalies over the MJO cycle are then mapped over the African domain (Fig. 4). To replace each eighth of the cycle in its context please refer to Fig. 2: convection is over equatorial Africa at phase $2 \pi / 0$, over the Maritime Continent from phase $\pi / 2$ to $\pi$, etc. The northern part of the domain in Fig. 4 confirms what was shown in Fig. 2: the main MJOinduced convection is found over equatorial Africa during the above-mentioned phase. The equatorially trapped convective clusters barely reach $15^{\circ} \mathrm{S}$. Farther south the OLR patterns are more complicated, and active convection is not synchronous with respect to that of the equatorial latitudes.

The convective signal appears particularly early over the southern part of Africa and has already dissipated when the clusters emerge along the equator. The first negative OLR anomalies are found over southern Angola and northern Namibia at phase $3 \pi / 4-\pi$, and more clearly at the following $\pi-5 \pi / 4$ phase, that is, when equatorial Africa experiences its phase of suppressed convection (Fig. 2). After that, these anomalies extend and shift southeastward over Botswana (phase $5 \pi / 4-3 \pi / 2)$. Then they intensify, propagate to the north, and reach Zimbabwe and southern Tanzania around phase $7 \pi / 4$. Conditions are now gathered for convection to develop at the very low latitudes, where the MJO-associated convective clusters are indeed observed at this time. A convective precursor is thus identified over Angola and Namibia. More important, the OLR field seems to locally and significantly respond to the MJO forcing. It is nevertheless noticed that MJOassociated convection does not seem to reach the southernmost part of South Africa.

Two questions arise now. (i) Are the OLR anomalies significantly triggered by the MJO over the region? (ii) Are the convective precursor and the northward migration of convection also detected by a local mode analysis (Goulet and Duvel 2000), which is particularly accurate for depicting $\mathrm{MJO}$-associated propagation patterns?

Figure 5 shows the results of an analysis of variance (ANOVA) between the OLR grid points and the eighths of the MJO cycle (i.e., $0-\pi / 4, \pi / 4-\pi / 2, \ldots, 7 \pi / 4-2 \pi$ ) to which each day of the period is assigned. The MJO phases significantly discriminate the fluctuations in the OLR values over major parts of the continent, and even of the surrounding Atlantic and Indian Oceans. Significance is also reached over Madagascar and the southwest Indian Ocean (SWIO) heights. In other words, intraphase variance is significantly lower than interphase variance over these regions.

South Africa seems to be located at the extreme periphery of the MJO extension domain, and its austral parts, which include the south coast and the Cape region, do not reach the $95 \%$ significance level. This particular location reinforces the interest of an analysis of 

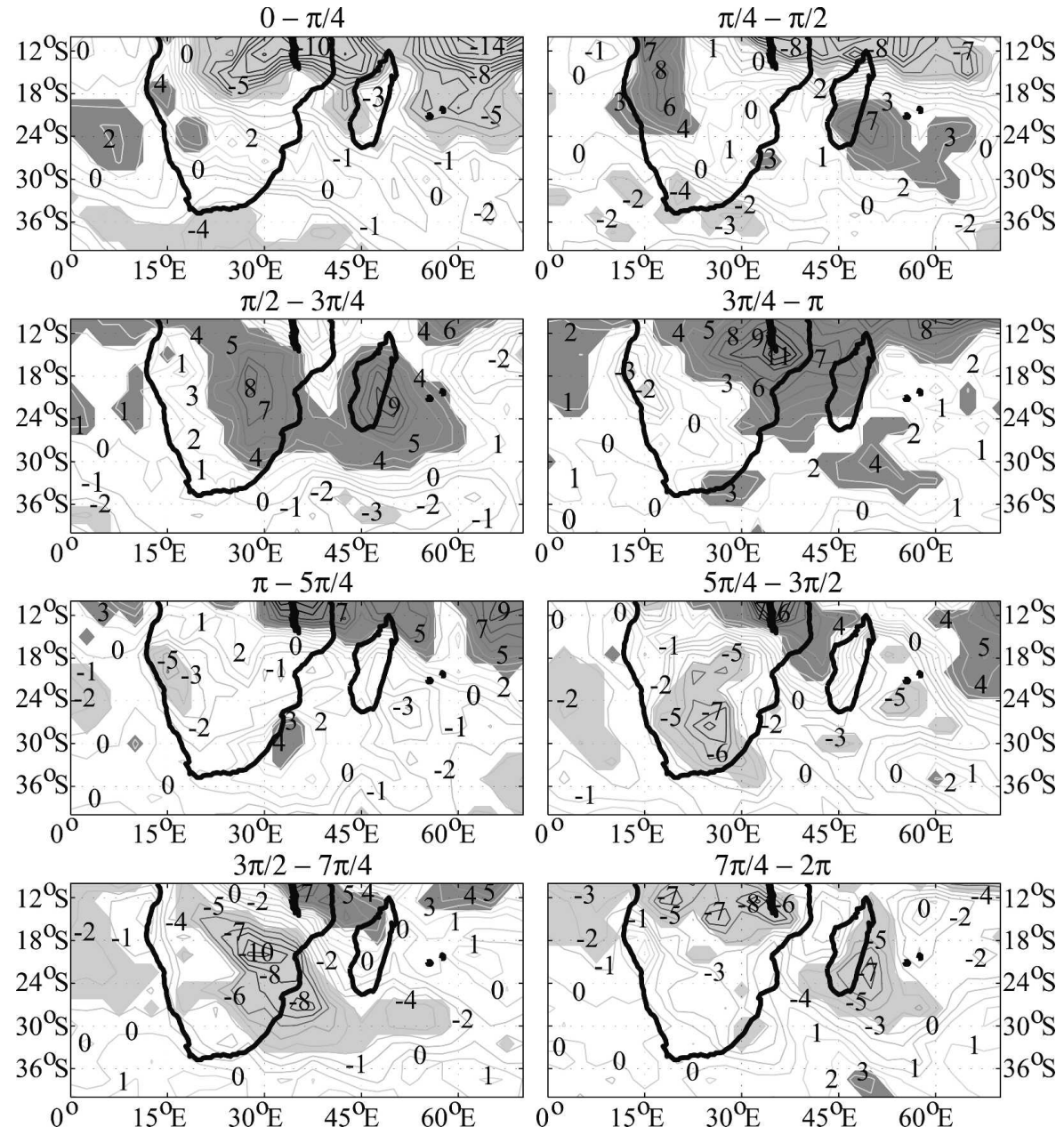

FIG. 4. Composite maps of deseasonalized OLR anomalies over the MJO cycle $\left(\mathrm{W} \mathrm{m}^{-2}\right)$, October-April 1974-1999. CI is $1 \mathrm{~W} \mathrm{~m}^{-2}$. Light (dark) gray shadings correspond to the negative (positive) OLR anomalies that are significant at the $95 \%$ level according to a $t$ test.

the daily rainfall records, since the influence of the MJO is logically not as strong as what is found over the core region of the oscillation. This aspect will be discussed in section 4 .

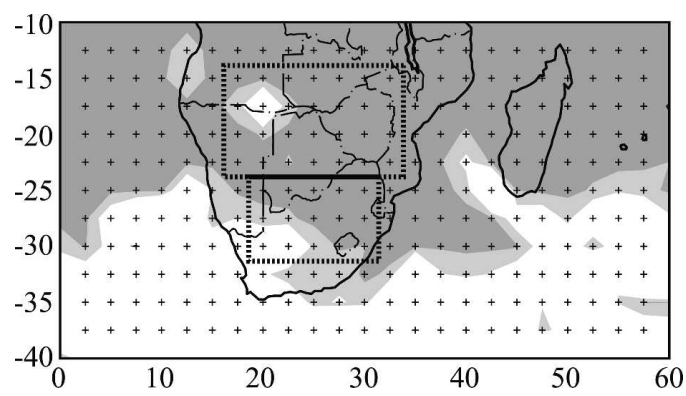

FIG. 5. Analysis of variance between the OLR grid points and the MJO eighths of the cycle such as defined in Fig. 4, OctoberApril 1974-99. Light (dark) gray shadings show the areas that are significantly modulated by the MJO phase at the 95\% (99\%) confidence level.

\section{b. Propagative pattern of the convective clusters}

The intraseasonal migration of large-scale convective clusters is objectively detected by applying a local mode analysis (LMA; Goulet and Duvel 2000) to the OLR field over southern Africa, for the ONDJFMA season. Basically, the algorithm proceeds as follows: A moving window runs through the study period, two successive steps being separated by a fixed lag. For each step a complex empirical orthogonal function is applied to the OLR field over the domain; when a peak of intraseasonal variance is detected the complex propagative pattern of the corresponding mode of convective variability is extracted. To ensure robust results a bandpass filtering of the input (OLR) field is needed, the length of the moving window must be longer than that of the expected modes of variability, and the lag between two iterations must be less. Additional details concerning the methodology are given in Goulet and Duvel (2000). 

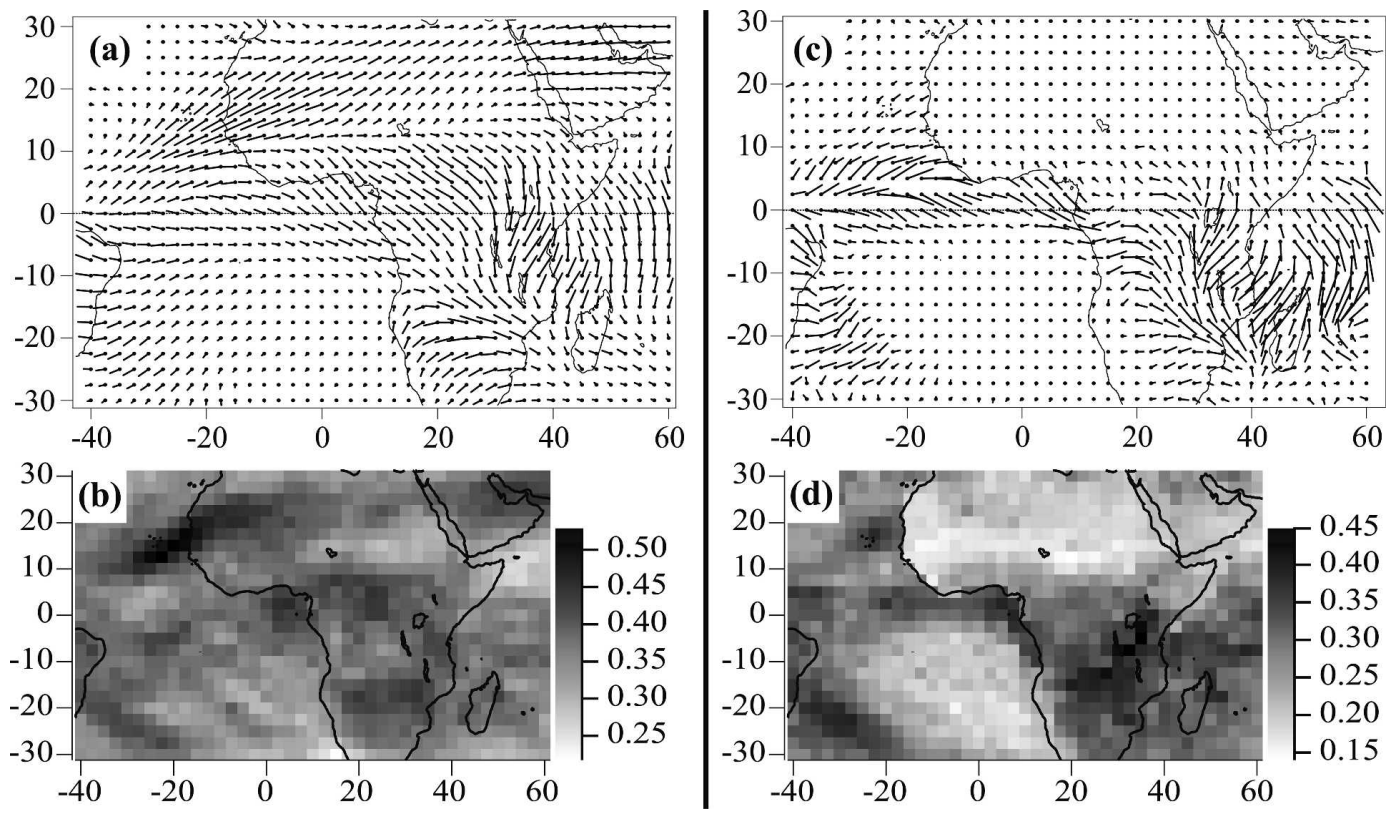

FIG. 6. (a) Mean propagation of the large-scale OLR intraseasonal perturbations such as detected by the local mode analysis algorithm (Goulet and Duvel 2000) for ONDJFMA 1979-2004. The amplitude of the modes is proportional to the segment length, and the phase at which the maximum perturbation occurs for each OLR grid point is represented as the angle of the corresponding segment. The propagation of OLR anomalies is seen as the clockwise increase of the angle with time (e.g., eastward propagation for a segment rotating clockwise toward the east). (b) Coherence of the OLR field (part of the overall intraseasonal variance that is triggered by the local modes, i.e., by the MJO events). (c) Same as in (a), but projection on the CMAP rainfall field. (d) Same as in (b), but for the CMAP rainfall field.

For the present work, the domain on which the LMA is applied is centered on Africa (Fig. 6). It is large enough $\left(100^{\circ}\right.$ in its latitudinal extension) to detect propagations and restricted enough to depict primarily intraseasonal modes of purely African convection. The period (1979-2004), slightly different from the remainder of the work, is forced by the necessity of continuity of the time series. To extract strictly intraseasonal oscillations, the length of the temporal moving window of the LMA is equal to 120 days and the lag between two successive steps is 5 days. The sensitivity of the results on these parameters is discussed in Goulet and Duvel (2000).

The perturbations induced in the rainfall field are documented by projecting the detected local modes, corresponding to intraseasonal peaks of variance in the input (OLR) field, on the CMAP rainfall estimates (Xie and Arkin 1997). To that end, the multivariate version of the LMA (Duvel and Vialard 2007) was used. The OLR field was preliminarily aggregated at the pentad (5 day) time scale to fit the CMAP temporal resolution. It was observed (not shown) that strictly similar results are obtained with the pentad version of the Global Precipitation Climatology Project (GPCP) dataset (Xie et al. 2003).
A first statement concerns the amplitude of the modulation of local convection by the MJO (Fig. 6a). It clearly appears that the detected modes of variability are more energetic over Africa during the southern summer season than the background noise of the atmosphere, which is fully consistent with Figs. 4 and 5. At the very low latitudes, the modes basically consist of a regional stationary state over the Congo basin, more generally embedded in the large-scale eastward propagation from the Atlantic basin (Foltz and McPhaden 2004) to the Indian Ocean (consistently with Fig. 2).

Over southern Africa, one observes more specifically a propagation of the convective clusters very close to the one obtained by composite analysis (Fig. 4). The large-scale OLR structures first appear over southern Angola-northern Namibia and then propagate southward and eastward to Botswana and Zimbabwe, where they reach their maximum. Over the Great Lakes region they propagate to the north, especially from Lake Malawi to Lake Victoria. In agreement with Fig. 4, intraseasonal convective anomalies then reach the equator and the main MJO-associated convective clusters. On average, the presence of a convective precursor over Angola and Namibia is thus confirmed. 


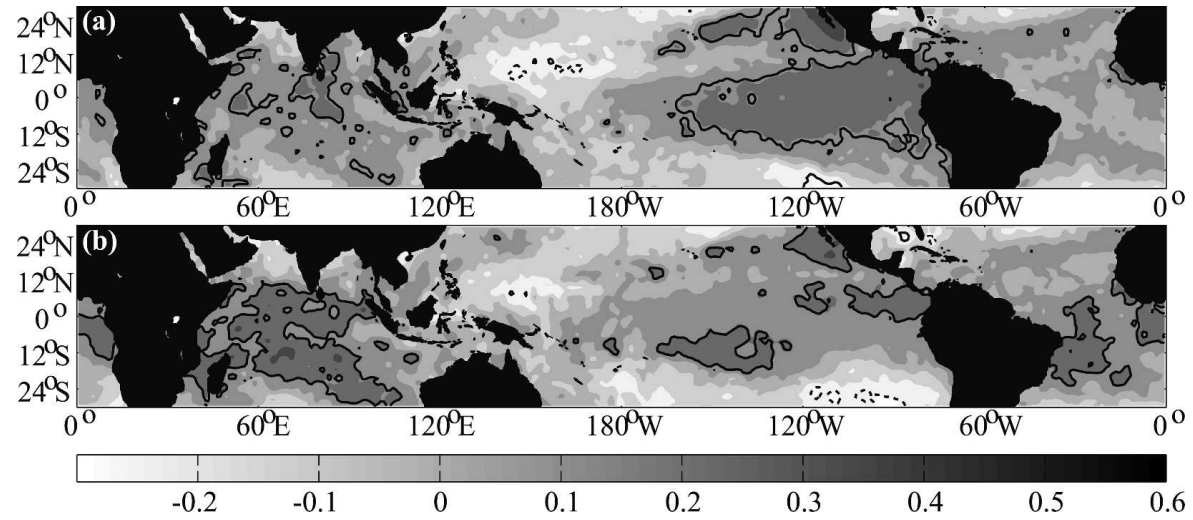

FIG. 7. Correlation patterns between the mean amplitude of the OLR local modes over the (a) TSA and (b) SSA regional indices (boxed in Fig. 5) and corresponding SST grid points after removal of the annual cycle, October-April 1979-2004. See legend for shading. Positive (negative) correlation values that are significant at the $95 \%$ level according to a Monte Carlo test are shown by the solid (dashed) black lines. This test considers the autocorrelation of the time series.

The coherence statistics (Fig. 6b) show that the local modes explain on average from $35 \%$ to $50 \%$ of the overall intraseasonal variability of the OLR field. These values are remarkably high over the Congo basin and southern Africa between $15^{\circ}$ and $25^{\circ} \mathrm{S}$, denoting a significant and nonnegligible influence of the MJO there.

The induced fluctuations in the rainfall field are depicted by Figs. 6c and 6d. On approximation they are consistent with the OLR propagative pattern (Fig. 6a), which demonstrates that a perturbation in the atmospheric convection logically generates a perturbation in the rainfall amount. However, since CMAP is partly derived from the OLR field (Xie and Arkin 1997), the consistency between these two datasets is thought to be slightly enhanced.

Large amplitudes are found over the equatorial Atlantic basin; following Foltz and McPhaden (2004) they are hypothesized to result from an intraseasonal modulation of the intensity of the trade winds, and thus of the intertropical convergence. Over Africa they are located in the Southern (summer) Hemisphere, where they denote significant fluctuations in the rainfall, mainly over the highlands.

Note that this pattern, consistent with Fig. 3, is also clearly reminiscent of the linear intertropical front usually observed over the Atlantic domain. The larger latitudinal extension of the MJO-influenced areas over Africa is also quite close to the mean location of the ITCZ during the austral summer season. The coherence values are slightly lower than for the OLR and show that the local modes, that is, the $\mathrm{MJO}$, are responsible for approximately $30 \%-35 \%(35 \%-40 \%)$ of the overall intraseasonal rainfall variability over South Africa (the Rift Valley and the Great Lakes).

\section{c. Interannual variability}

Southern African rainfall shows marked interannual fluctuations, principally associated with ENSO (Dyer 1979; Lindesay 1988a,b; Lindesay and Vogel 1990) almost since 1970 (Richard et al. 2000), that is, the period analyzed here. A warm event is often concomitant with anomalously low seasonal rainfall amounts. Mason (1995) and Reason and Mulenga (1999) also showed that such fluctuations were related to the Indian Ocean SST. Therefore, the interannual variability of the amplitude of the local modes (i.e., that of the intraseasonal fluctuations in the OLR field such as detected by the LMA; Fig. 6a) over southern Africa was investigated, and a possible implication of ENSO was particularly examined. In other words, our aim is to establish whether the most energetic intraseasonal perturbations in atmospheric convection preferentially occur during El Niño (warm) or La Niña (cold) years.

To document this aspect two regional indexes of local mode amplitudes were computed, respectively, corresponding to "tropical" southern Africa (TSA; $15^{\circ}$ $\left.22.5^{\circ} \mathrm{S}, 17.5^{\circ}-32.5^{\circ} \mathrm{E}\right)$ and "subtropical" southern Africa (SSA; $\left.25^{\circ}-30^{\circ} \mathrm{S}, 20^{\circ}-27.5^{\circ} \mathrm{E}\right)$. These areas roughly correspond to the two groups of rain gauges (Fig. 1) used for section 4; they are shown as boxes in Fig. 5 . The mean amplitude of the local modes is spatially averaged within these two regions, to obtain a single amplitude value per area and per local mode. The two indexes are then correlated with the synchronous HadiSST grid points (i.e., the SST field during the month of occurrence of the local mode) after removal of the annual cycle. The spatial patterns of the teleconnections are shown in Fig. 7. 
The amplitude of the local modes over the TSA region (Fig. 7a) shows significant teleconnections with the SST in the eastern Pacific basin - a pattern clearly reminiscent of El Niño. The positive sign of the correlations indicates that the intraseasonal modulation of southern African convection is stronger during El Niño years, that is, when convection is locally less active (Jury 1997; Richard et al. 2000). Analyses based on the standard deviation of the 20-75-day filtered OLR, used as an alternative proxy for the local amplitude of the MJO modes, lead to very similar results. Even if deep atmospheric convection is more developed during La Niña years, it is more significantly modulated, at the intraseasonal time scale, during El Niño events.

The teleconnections with the SSA index (Fig. 7b) show generally weaker teleconnections with ENSO, especially over the eastern Pacific basin. The most significant patterns are indeed found over the Indian Ocean, the local modes of African convection being more energetic over southern Africa under warm conditions in the central and western parts of the basin. Nevertheless, this spatial pattern is also very close to the El Niñoassociated SST anomalies over the Indian Ocean, as depicted in Reason et al. (2000) and Xie et al. (2002). ENSO is therefore thought to be (partially) involved in the teleconnections, as for the TSA region. In addition, positive significant correlations are also found over the Atlantic basin.

Atmospheric convection is thus more strongly modulated by the MJO over southern Africa when warm conditions prevail in the tropical belt, especially in the Indo-Pacific basin. The response of the rains to these intraseasonal perturbations in the southern African atmospheric convection is now to be examined.

\section{Response of the rainfall to the MJO}

The "local modes" of African convection suggest that southern African rainfall is significantly modulated by the MJO at the intraseasonal time scale (Figs. 6c,d). The reliability of satellite estimates is however questionable. As an alternative, this section is based on daily rain gauge records.

\section{a. Regionalization and composite analysis}

Homogeneous rainfall indices are obtained by a principal component analysis with varimax rotation, applied on the 10-day low-pass-filtered daily rain gauge records, for the October through April season. The filtering process has been used to remove high-frequency noise that could interfere with lower-frequency signals. The rainfall indices are thus homogeneous spatially at time scales that are compatible with the intraseasonal frequency range analyzed here.

As the two groups of stations (Fig. 1) are not available for the same period, only the subtropical ones are considered here. The first five PCs, explaining $55 \%$ of the initial variance of the filtered rainfall and significant according to a scree test, were rotated. The five corresponding rainfall indices are then constituted by averaging the station records most significantly (loadings $\geq 0.5$ ) correlated with the scores of the rotated PCs (RPCs). It was verified that similar results are obtained when working directly on the scores associated to each RPC (not shown). Though low-frequency signals such as the MJO are expected to be found at the subcontinental scale, the regionalization that is proposed here makes it possible to obtain coherent rainfall indices, independently of the effects of the MJO itself.

Note that, though the composite anomalies shown hereafter are calculated on low-pass-filtered time series, it was also verified that similar results are obtained with unfiltered ones (not shown). The significance of the results presented is therefore not enhanced by the filtering technique but denotes a real intraseasonal signal in the southern African rains.

Composite of rainfall anomalies over the MJO cycle are shown in Fig. 8. Four out of the five indexes (RPCs $1,2,3$, and 5, except the western Cape region) clearly exhibit a dry and a humid phase over the MJO cycle (centered on $3 \pi / 4$ and $3 \pi / 2$, respectively). These opposite phases are characterized by rainfall amounts significantly lower (higher) than the annual cycle. The phase locking is in strong accordance with the OLR anomalies shown in Fig. 4. Analyses of variance between rainfall anomalies and the MJO phases (eighths of cycle) estimate that the confidence level is higher than $99 \%$ for these four indexes. Moreover, the observed intraseasonal fluctuations in the precipitation amount correspond to similar fluctuations in the number of stations recording heavy rainfall, which shows that rain-causing mechanisms typically have a large (subcontinental) spatial extension.

However, the five indexes are not similarly affected by MJO activity. The response of the rains over the RPC 3 area (Northern Province of South Africa) seems to be the strongest; on the other hand, rainfall over the RPC 4 (western Cape Province) region is very weakly modulated at the MJO time scale. From one index to another, the humid phase shows amounts that are from $40 \%$ to $80 \%$ higher than the dry phase. For the RPC 4 area the value is $27 \%$ only, but more importantly the extreme (wet and dry) phases for this index are not locked on MJO phase bins that show particular extremes in terms of atmospheric convection over south- 

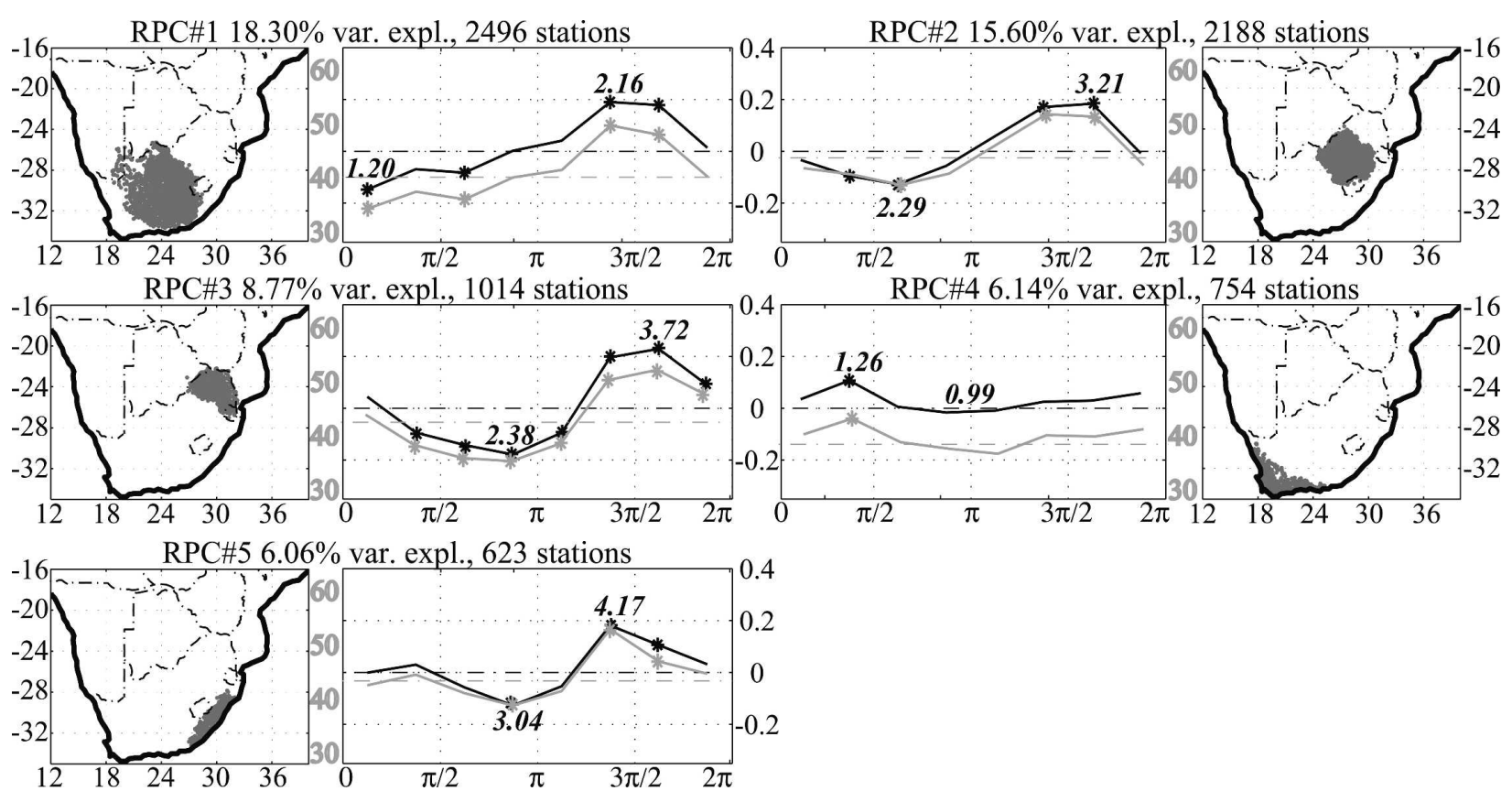

FIG. 8. Composites of deseasonalized rainfall anomalies over the intraseasonal cycle for the five regional indices (black lines) and mean part of stations (\%) experiencing precipitation higher than the annual cycle for each MJO phase and within each index (gray lines). Asterisks denote anomalies that are significant at the $95 \%$ level according to a $t$ test. The corresponding raw rainfall amount (i.e., without removal of the annual cycle) over the regional index for the dry and humid phases is also labeled on the figure (mm day ${ }^{-1}$ ). The outer panels show the maps of the rain gauge stations constituting each rainfall index.

ern Africa (Fig. 4). Besides, the latter index is not significantly discriminated by the MJO according to an ANOVA.

Geographically the less influenced areas are the ones located in the southern part of the domain, while the regions that strongly respond to the intraseasonal oscillation are located farther north. These results are consistent with those shown in Fig. 5, which points out that atmospheric convection over the extreme southwest of Africa (Cape Town and surrounding areas, corresponding to the RPC 4 index), is indeed not significantly affected by the MJO. More generally, a southwestnortheast gradient across South Africa is found in terms of influence of the intraseasonal oscillation on the daily rainfall amounts.

Figure 9 shows the results of power spectrum analyses applied to the five rainfall indexes. The intraseasonal signal in the time range of the MJO does not clearly appear, though peaks of periodicities in the 3060 -day range reach the $95 \%$ significance level for the three first RPCs. It is therefore suggested that the MJO is undoubtedly involved in a nonnegligible part of the southern African rains' subseasonal variability, but many other factors at both shorter and longer time scales may strongly interfere with its signal. Possible influences of the midlatitude circulation and interac- tions with the tropical atmospheric dynamics are particularly hypothesized to play a predominant role, in accordance with what was shown in many previous works.

\section{b. Extension to tropical Africa}

The increasing influence of the MJO to the lower latitudes (Figs. 5 and 8) justifies the extraction of tropical rain gauge stations, despite their shorter period of records and their missing values. The regional indexes obtained by rotated PCA are shown on Fig. 10; the methodology used is the same as for the section 3a. As moving averages were used to fill up missing values, the time series have also been 10-day low-pass filtered to allow comparison with the subtropical domain. Once again the effects of the filter on the results are negligible (not shown) and do not affect our conclusions at the intraseasonal (MJO) time scale. Three PCs, explaining $56 \%$ of the initial variance and significantly separated from the others by a scree test, are here retained.

The three corresponding indices also present a dry and a humid phase over the intraseasonal cycle (Fig. 10), which are both locked on suppressed/enhanced convection anomalies over the continent (Fig. 4). Note 

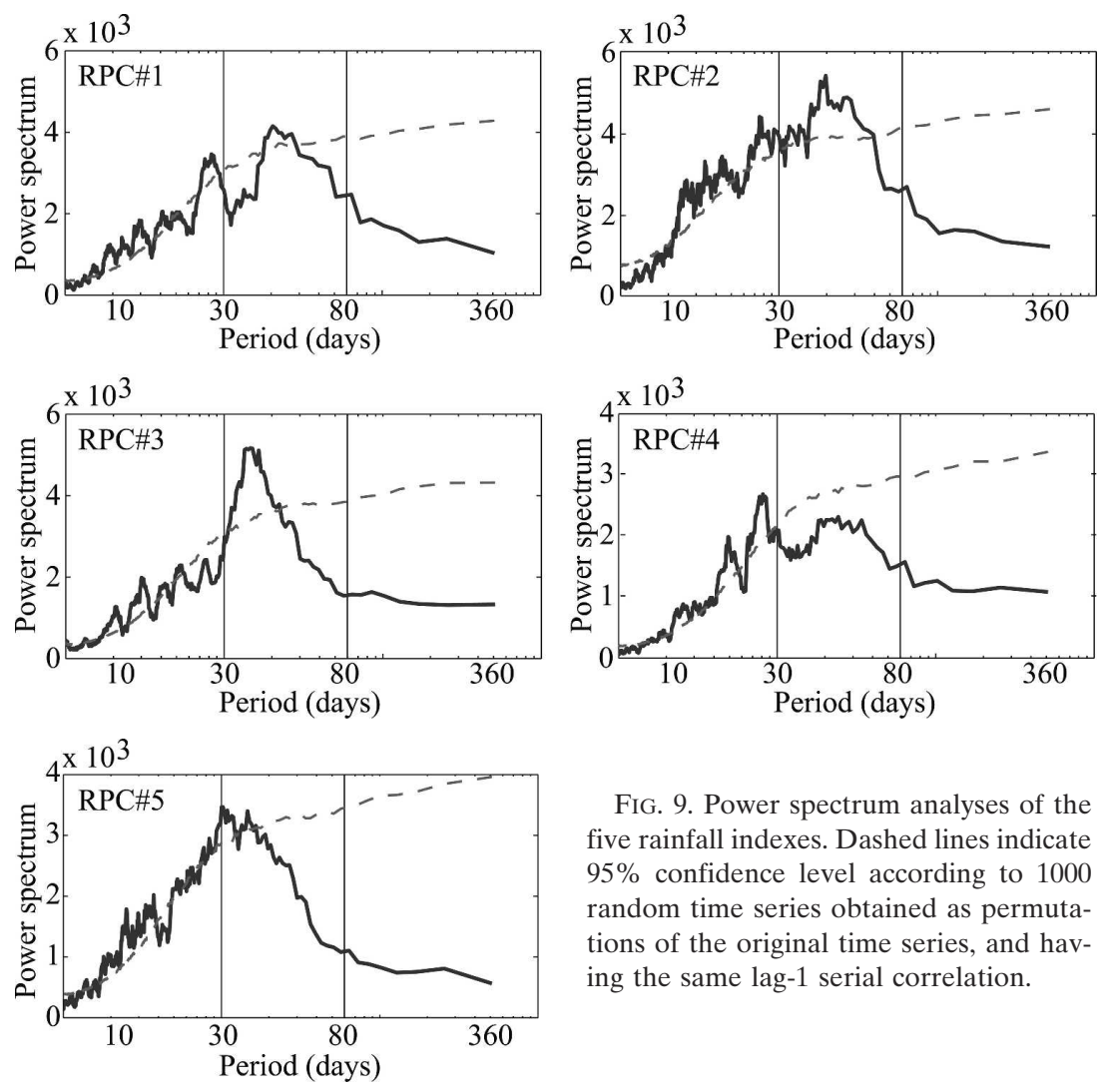

FIG. 9. Power spectrum analyses of the five rainfall indexes. Dashed lines indicate 95\% confidence level according to 1000 random time series obtained as permutations of the original time series, and having the same lag- 1 serial correlation.

that the dry and wet phases tend to occur later in the RPC 1 region (Zimbabwe), and sooner in RPC 3 (western Botswana and eastern Namibia), in accordance with the northeastward propagation of convective clusters (Figs. 4 and 6) over the area. Rainfall anomalies are also significantly discriminated by the MJO phases (confidence level higher than $99 \%$ according to an ANOVA). Importantly, the amplitude of the rainfall intraseasonal cycle, that is, the difference between the mean rainfall amount during the dry and the humid phase, is higher for the northern index (RPC 1) than for the central and southern ones. An increased influence of the MJO is confirmed by the power spectrum analyses shown in Fig. 11. The periods in the 30-60-day time range appear to be significant within the three regions, denoting a strengthened MJO forcing on the rains.

These points suggest that the southwest-northeast gradient observed across the subtropical region continues across the tropical domain. By its location at the edge of the MJO core area (shown in Fig. 3), southern Africa is heterogeneously submitted to the influence of the intraseasonal oscillation. Logically, the influence of the MJO is getting higher from the subtropical to the equatorial latitudes.

\section{c. Atmospheric dynamics}

The atmospheric dynamics associated with the rainfall (Figs. 8, 10) and OLR (Fig. 4) intraseasonal fluctuations are here investigated. Preliminary analyses (not shown) lead to identifying the 700-hPa geopotential level as the most directly implicated in the temporal alternation of dry and humid phases over southern Africa. Specific humidity and moisture fluxes are particularly seen to significantly respond to the MJO forcing and are therefore presented in this section. As a composite analysis separating the different MJO eighths of the cycle basically exhibits deseasonalized anomalies, without any reference to the mean fields, Fig. 12 shows the average situation observed during austral summer.

A continent-ocean contrast is schematically found for specific humidity, air masses over Africa (and to a lesser extent Madagascar) showing higher amounts. However the oceanic domain is not homogeneous spatially, and lower latitudes logically convey more water vapor in relation with their higher air temperature. At this level horizontal moisture fluxes are quite weak over the tropical Indian Ocean. The strongest fluxes are embedded in the westerly circulation in the midlati- 
RPC\#1 23.64\% var. expl., 27 stations

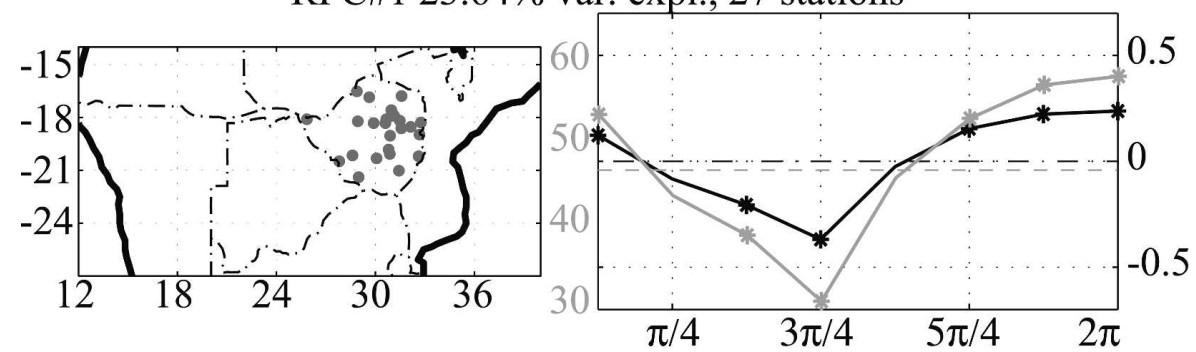

RPC\#2 19.07\% var. expl., 23 stations

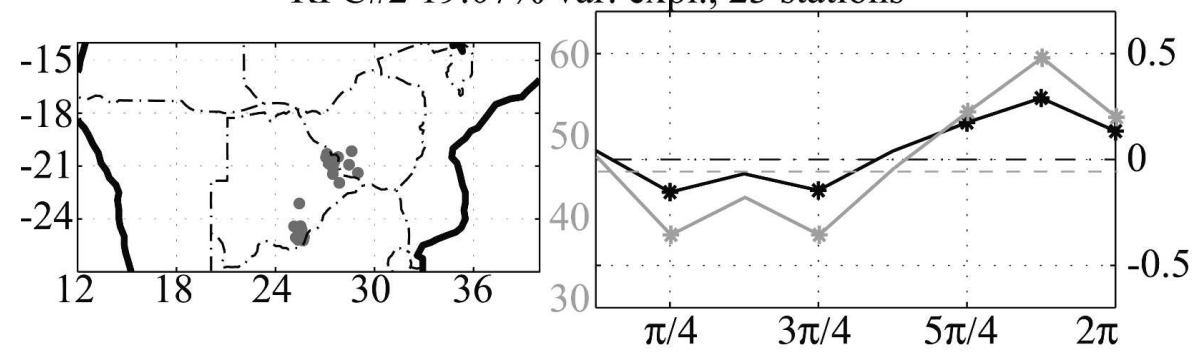

RPC\#3 13.29\% var. expl., 14 stations

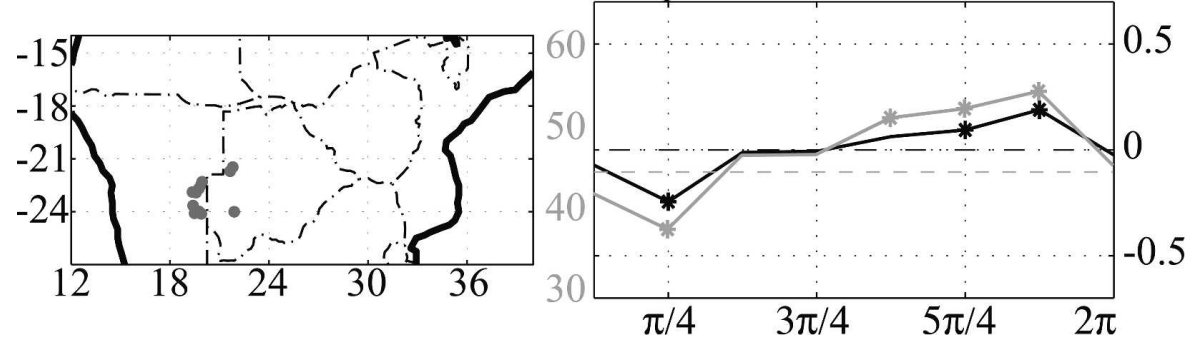

FIG. 10. Same as in Fig. 8, but for the TSA region.

tudes, and in the midtropospheric easterly flow over the Congo basin under the Tropics.

After removing the annual cycle, Fig. 13 shows the humidity and moisture flux composite anomalies over the intraseasonal cycle. The most energetic signal in the moisture fluxes is logically found in the northern part of the domain and consists in an intraseasonal modulation of the midtropospheric easterly flow by the MJO. Analyses on raw fields (i.e., without removal of the annual cycle) show that this subequatorial flux strongly weakens and almost interrupts during given MJO phases and is on the contrary greatly enhanced during the opposite half-cycle. The situation is not so clear for humidity anomalies, and pockets of significant anomalies often spread out over the overall area.

In detail, significant positive humidity anomalies are found over Angola and Namibia at $3 \pi / 4$, that is, when the first negative OLR anomalies develop there (Fig. $4)$. These anomalies extend then over the overall subcontinent and correspond to the rainfall peaks found in Figs. 8 and 10 at this time of the cycle. Besides, the humid phase over southern Africa (phases $5 \pi / 4$ to
$7 \pi / 4)$ is concomitant with a reinforcement of the easterly flux over tropical Africa, coupled to northerly anomalies over Zambia, Botswana, and Zimbabwe. More importantly, easterly fluxes in the tropical latitudes are also reinforced over the western Indian Ocean. The mean moisture fluxes there are on average very weak (Fig. 12) and small anomalies are liable to reverse the direction of the instantaneous fluxes. It is then concluded that reversed moisture fluxes from the Indian Ocean to Africa are favorable for rainfall over the southern part of the continent, since they are also related to significant meridional anomalies over Angola liable to advect moisture to the subtropical latitudes. These circulation patterns are seen to respond to an intraseasonal modulation of the SWIO heights, and correspond here to anticyclonic anomalies from $5 \pi / 4$ to $7 \pi / 4$ over Africa.

In contrast, the dry phase ( $\pi / 4$ to $3 \pi / 4)$ is associated with southerly anomalies over southern Africa and with a weakening of the midtropospheric easterly flow over the Congo basin. This pattern is consistent with the mean field (Fig. 12), as midlatitude air masses convey 

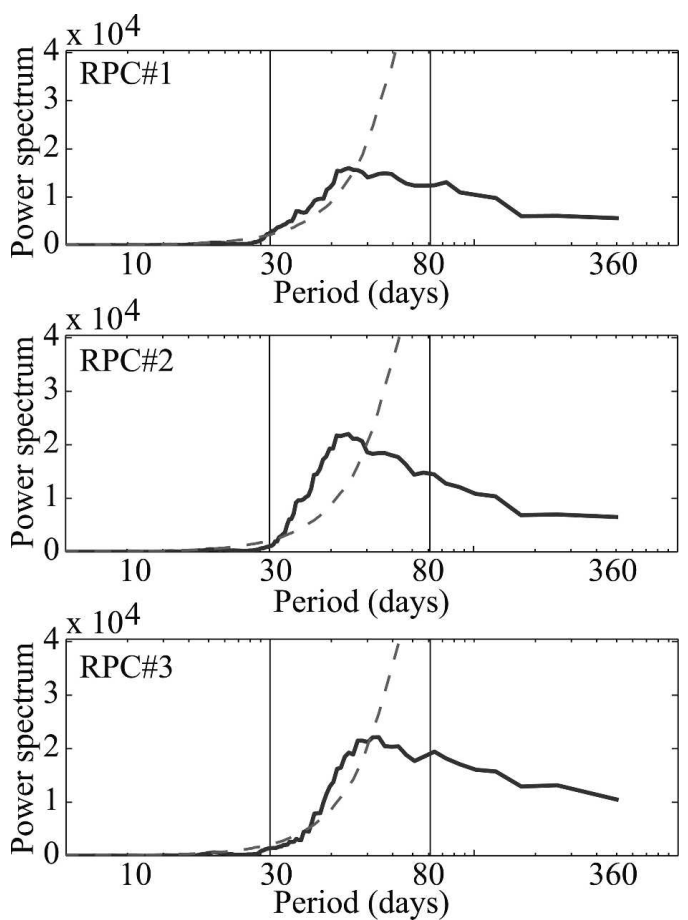

FIG. 11. Same as in Fig. 9, but for the TSA region.

less humidity. Therefore, air incursions over Africa logically favor dryness.

\section{d. Intraseasonal modulation of the SWIO OLR dipole}

At the interannual time scale, Jury (1992) and Richard (1994) found an OLR dipole over the SWIO/ southeast Africa region that was shown to significantly trigger rainfall amounts over southern Africa. Schematically the spatial pattern shows a contrast between East Africa and the oceanic domain in the north of Madagascar on the one hand, and the hinterland parts of the African continent in the south of $15^{\circ} \mathrm{S}$ on the other hand. The authors showed that when atmospheric convection is anomalously active over one of these areas it tends to be anomalously weak over the other.

A similar spatial structure is found at the synoptic scale and is interpreted as the signature of the TTT systems, which denote strong interactions between the tropical and temperate circulations over the area (Todd and Washington 1999; Washington and Todd 1999; Todd et al. 2004). Southern Africa and the SWIO is one of the three known preferred locations for such tropical-temperate interactions in the Southern Hemisphere (Streten 1973). Unlike its counterparts, namely the South Atlantic and South Pacific convergence zones, the TTT systems (corresponding to the "south Indian convergence zone"; Cook 2000) are mainly restricted to the austral summer months, and it is thought that a large part of interannual rainfall variability over the region is related to changes in the preferred location and frequency of these systems (Cook 2000; Todd et al. 2004).

Interestingly, similar oppositions are also found, at the intraseasonal time scale, at given phases of the MJO. They can for instance be observed on the composite maps of OLR (Fig. 4) and specific humidity (Fig. 13) anomalies, especially from $\pi / 4$ to $\pi / 2$ on the one hand, and symmetrically from $5 \pi$ to $7 \pi / 4$ on the other hand. The MJO propagative patterns, extracted with the LMA algorithm (Fig. 6), also show that convection does not occur in phase between the two regions. To ascertain the potential forcing of the MJO on the dipole, a dipole index (DI) is computed as the difference of the averaged OLR daily grid points included in the area $15^{\circ}-25^{\circ} \mathrm{S}, 17.5^{\circ}-30^{\circ} \mathrm{E}$, minus the grid points in the area $10^{\circ}-17.5^{\circ} \mathrm{S}, 47.5^{\circ}-60^{\circ} \mathrm{E}$ (boxed in Fig. 12). These boxes are in accordance with the spatial patterns described in Jury (1992). The resulting time series is then submitted to (i) a composite analysis against the MJO phases and (ii) a spectral analysis; the results are shown in Fig. 14.

The composite analysis (Fig. 14a) shows that the DI series is significantly modulated by the MJO, a significant "positive" phase (convection stronger over the ocean and weaker over Africa) and a more pronounced "negative" one alternating over the intraseasonal cycle. These results are consistent with those shown in Figs. 4 and 13. The MJO phases discriminate the values of the DI at a confidence level higher than $99 \%$ according to an ANOVA. Logically, the negative DI phase corresponds to the humid period for southern Africa (Figs. 8, 10).

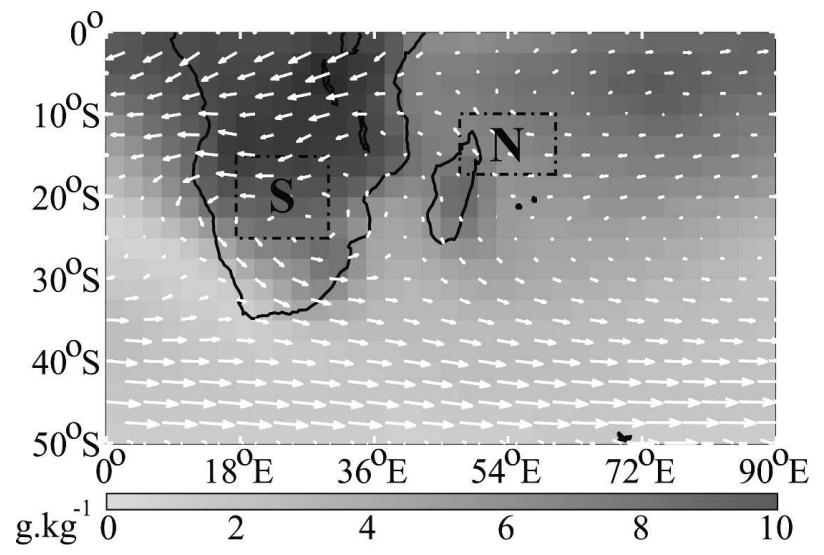

FIG. 12. Mean specific humidity field at $700 \mathrm{hPa}\left(\mathrm{g} \mathrm{kg}^{-1}\right)$ for the ONDJFMA season. Period of analysis is 1979-99. See legend for shading. The arrows show the mean moisture fluxes $\left(\mathrm{m} \mathrm{s}^{-1} \mathrm{~g}\right.$ $\mathrm{kg}^{-1}$ ) during the same period. The north $(\mathrm{N})$ and south (S) OLR indexes used for the calculation of the dipole index are shown as boxes. 

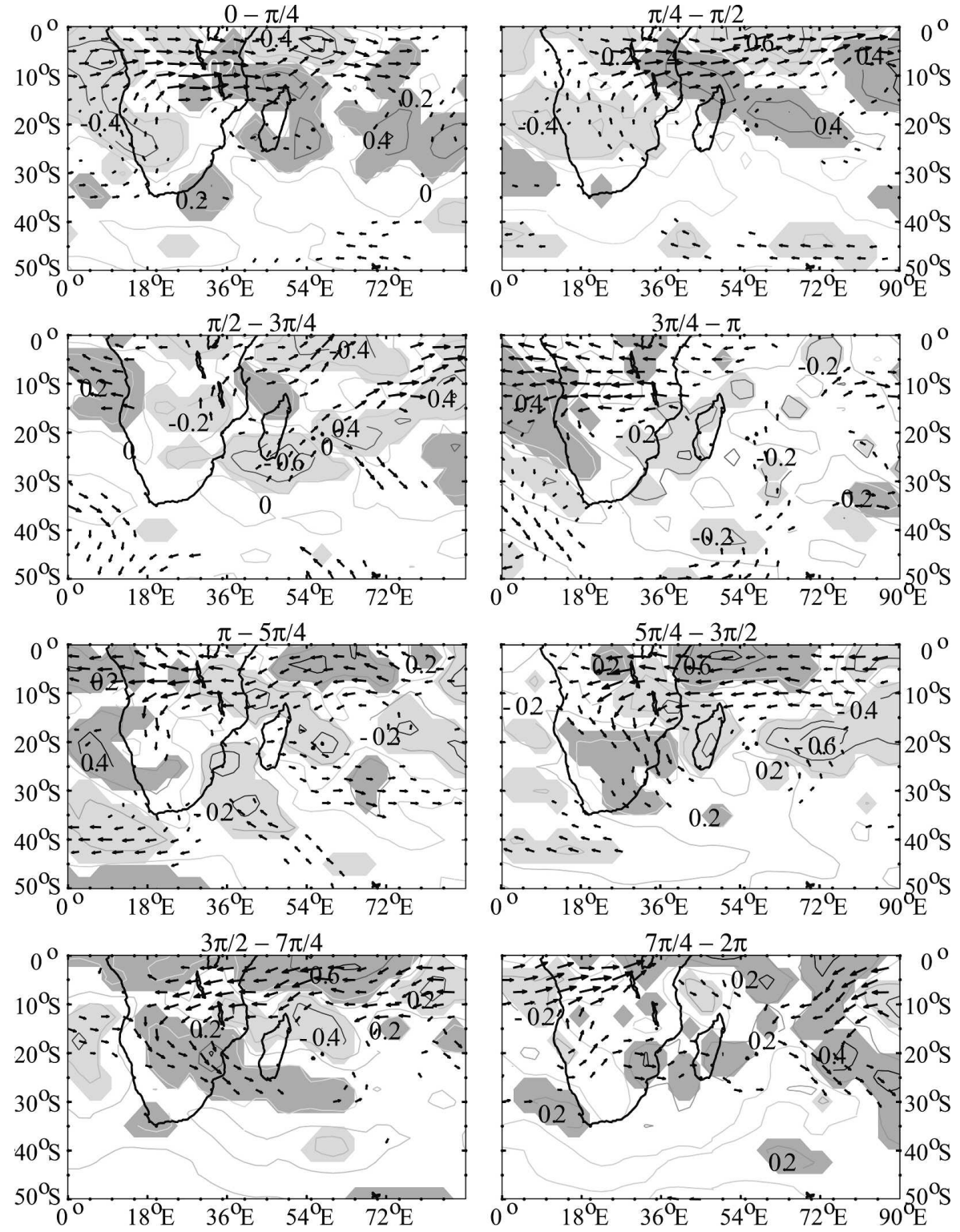

FIG. 13. Composite maps of specific humidity deseasonalized anomalies at $700 \mathrm{hPa}\left(\mathrm{g} \mathrm{kg}^{-1}\right)$ over the MJO cycle. CI is $0.2 \mathrm{~g} \mathrm{~kg}^{-1}$. Dark gray (light gray) shadings show significant positive (negative) anomalies according to a $t$ test at the $95 \%$ level. The arrows show corresponding moisture fluxes deseasonalized anomalies at $700 \mathrm{hPa}$. The only anomalies that are significant according to a Hotelling $t^{2}$ test at the $95 \%$ level are represented. The $t^{2}$ test is the multivariate generalization of the $t$ test; it is here applied to the meridional and zonal components of the moisture fluxes.

The results of the spectral analysis (Fig. 14b) show a peak of highly significant periods between 35 and 80 days. In details, the northern and southern poles, as well as the DI series to a lesser extent, exhibit marked periodicities at 35-40 days, and stronger ones between 50 and 80 days. The first peak is thought to be directly related to the MJO, while the second one, though not fully incompatible with its typical time scales, is obviously driven by other forcings. These values finally sug- gest that, even if the oscillation is involved in the DI intraseasonal fluctuations (Fig. 14a), it is not the only forcing mechanism that has an impact on this mode of convective variability. The interest is, however, that dipolar structures materialize at time scales between the synoptic (Todd and Washington 1999; Washington and Todd 1999; Todd et al. 2004) and the interannual (Jury 1992; Richard 1994) ones, which were the only time scales for which the dipole was observed to date. 

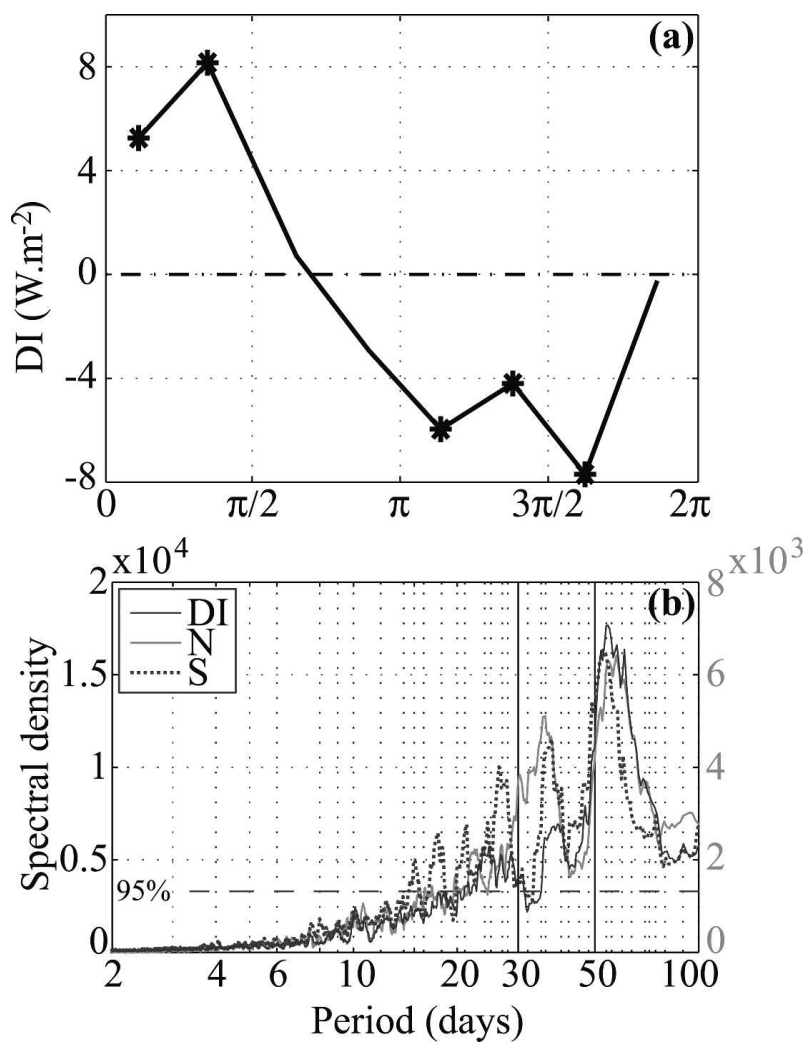

FIG. 14. (a) Composite analysis of the OLR dipole index (W $\mathrm{m}^{-2}$ ) over the MJO cycle. Asterisks denote anomalies that are statistically different from the average value according to a $t$ test (95\% level). (b) Spectral analysis of the dipole index series. The dashed line shows the $95 \%$ confidence level according to a Monte Carlo test.

\section{Summary and discussion}

The study shows that the Madden-Julian oscillation (MJO) has a nonnegligible impact on southern African rainfall and atmospheric convection variability. Significant statistical relationships are found for the austral summer season, extending from October through April. On average, convective clusters are seen to propagate across Africa, from the Angola and Namibia coast eastward to Botswana and then northward to Tanzania, where they reach the more developed equatorial clusters. It is also shown that the MJO events account for $35 \%-40 \%$ of the overall intraseasonal variance of the OLR field over the region.

Consequently, as atmospheric convection is regionally triggered by the MJO, a "humid" and a "dry" phase typically alternate over the cycle and across the domain. They respectively correspond to significant northerly (southerly) moisture flux anomalies over tropical Africa. These anomalies are seen to favor (inhibit) atmospheric convection over the southern part of the continent. They are also related to a strengthening (weakening) of the midtropospheric $(700 \mathrm{hPa})$ easterly flow found over the Congo basin at the near-equatorial latitudes. These anomalies in the dynamics are also related to a strengthening (weakening) of the SWIO heights. Thus, MJO-associated rainfall events show large-scale patterns, and they are observed at the regional scale over the domain and not in a limited number of rain gauge stations.

From one year to another, marked fluctuations are found in the amplitude of the modulation of atmospheric convection by the MJO across the area. It is established for years that El Niño events are associated with droughts over southern Africa. We show that atmospheric convection tends to be more strongly modulated by the MJO when warm conditions prevail in the tropical belt, especially in the Indian and eastern Pacific basins. Intraseasonal convection variability is higher during El Niño, while the convection itself is less active.

Composite analyses over the MJO cycle and spectral analyses on rainfall indexes seem however to show conflicting results. The first ones undoubtedly result in a strong (and highly significant) influence of the MJO. The latter fail to show marked and unambiguous 3060-day periodicities, except for the northern part of the domain where the role of the oscillation is obvious. Our hypothesis is that higher-frequency modes of variability may interfere with the intraseasonal time scale.

In addition to its significant impacts on the rainfall field over southern Africa, the MJO is here shown to statistically trigger the southern Africa-SWIO convection dipole. During phases $3 \pi / 2$ to $2 \pi$ in particular, one observes consistent anomalies displaying increased (decreased) convection over the inland part of southern Africa (north of Madagascar), leading to strong negative DI anomalies (Figs. 4 and 14), wet anomalies for most of the rainfall indices (Figs. 8 and 10), and changes in moisture transport at the $700-\mathrm{hPa}$ level. The latter roughly correspond to an enhanced water vapor flux from the tropical Indian Ocean to the east of $35^{\circ} \mathrm{E}$, and to an enhanced moisture transport along a band oriented northeast-southwest (Fig. 13).

Consequently, significant periodicities in the dipole index time series are found between 35 and 80 days, with two individualized peaks centered on 35-40 days and 50-80 days. The role of the MJO, though statistically significant, is thus relative; it is suggested that it is essentially through the 35-40-day peak, while the other one probably relates to other forcings.

The MJO finally accounts for one of the multiple atmospheric processes that trigger intraseasonal rainfall distribution over southern Africa. However, as pointed out in previous works, it is not the dominant one that reflects the interactions between the tropical atmo- 
sphere and the midlatitude dynamics. Additional analyses are now needed to relate the variability of the synoptic-scale "TTT" systems and the MJO life cycle.

Acknowledgments. This work was carried out as a part of the LOTI-VCI project funded by the French Programme National d'Etudes de la Dynamique du Climat (PNEDC). Rainfall data were provided by the South African Water Research Commission to the members of the PICS 1650 program of the CNRS. The authors are also indebted to Dr. Jean-Philippe Duvel, CNRS LMD, Paris, for his help, explanations, and advice concerning the use of the LMA algorithm. Nicolas Fauchereau is funded by a UCT post-doctoral fellowship and thanks Dr. Mathieu Rouault and Pr. Chris Reason for useful discussions on the paper.

\section{REFERENCES}

Cook, K. H., 2000: The South Indian convergence zone and interannual rainfall variability over Southern Africa. J. Climate, 13, 3789-3804.

Duvel, J.-P., and J. Vialard, 2007: Indo-Pacific sea surface temperature perturbations associated with intraseasonal oscillations of the tropical convection. J. Climate, 20, 3056-3082.

Dyer, T. G. J., 1979: Rainfall along the east coast of Southern Africa, the Southern Oscillation and the latitude of the subtropical high pressure belt. Quart. J. Roy. Meteor. Soc., 105, 445-451.

Fink, A., and P. Speth, 1997: Some potential forcing mechanisms of the year-to-year variability of the tropical convection and its intraseasonal (25-70 day) variability. Int. J. Climatol., 17, 1513-1534.

Foltz, G. R., and M. J. McPhaden, 2004: The 30-70 day oscillations in the tropical Atlantic. Geophys. Res. Lett., 31, L15205, doi:10.1029/2004GL020023.

Goff, J. A., and S. Gratch, 1946: Low-pressure properties of water from -160 to 212 F. 52d Annual Meeting of the American Society of Heating and Ventilation Engineers, New York, NY, ASHVE, 95-122.

Goulet, L., and J.-P. Duvel, 2000: A new approach to detect and characterize intermittent atmospheric oscillations: Application to the intraseasonal oscillations. J. Atmos. Sci., 57, 2397 2416.

Graham, N. E., and T. P. Barnett, 1987: Observations of sea surface temperatures, convection and surface wind divergence over tropical oceans. Science, 238, 657-659.

Harrison, M. S. J., 1984: A generalized classification of South African rain-bearing synoptic systems. J. Climatol., 4, 547560.

— 1986: A synoptic climatology of South African rainfall variations. Ph.D. thesis, Department of Geography, University of Witwatersrand, $341 \mathrm{pp}$.

Hendon, H. H., and B. Liebmann, 1990a: A composite study of onset of the Australian summer monsoon. J. Atmos. Sci., 47, 2227-2239.

—, and - 1990b: The intraseasonal (40-50 day) oscillation of the Australian summer monsoon. J. Atmos. Sci., 47, 29092923.

_ C. Chang, and J. D. Glick, 1999: Interannual variation of the
Madden-Julian oscillation during austral summer. J. Climate, 12, 2538-2550.

Hsu, H.-H., and M.-Y. Lee, 2005: Topographic effects on the eastward propagation and initiation of the Madden-Julian oscillation. J. Climate, 18, 795-809.

Jury, M. R., 1992: A climatic dipole governing the interannual variability of convection over the SW Indian Ocean and SE Africa region. Trends Geophys., 1, 165-172.

_ 1997: Interannual climate modes over Southern Africa from satellite cloud OLR 1975-1994. Theor. Appl. Climatol., 57, 155-163.

_, 1999: Intra-seasonal convective variability over Southern Africa: Principal Component Analysis of pentad outgoinglongwave radiation departures 1976-1994. Theor. Appl. Climatol., 62, 133-146.

Kalnay, E., and Coauthors, 1996: The NCEP/NCAR 40-Year Reanalysis Project. Bull. Amer. Meteor. Soc., 77, 437-471.

Kanamitsu, M., W. Ebisuzaki, J. Woollen, S.-K. Yang, J. J. Hnilo, M. Fiorino, and G. L. Potter, 2002: NCEP-DOE AMIP II reanalysis (R-2). Bull. Amer. Meteor. Soc., 83, 1631-1643.

Kijazi, A. L., and C. J. C. Reason, 2005: Relationships between intraseasonal rainfall variability of coastal Tanzania and ENSO. Theor. Appl. Climatol., 82, 153-176.

Knutson, T. R., and K. M. Weickmann, 1987: 30-60 day atmospheric oscillations: Composite life cycles of convection and circulation anomalies. Mon. Wea. Rev., 115, 1407-1436.

Levey, K. M., and M. R. Jury, 1996: Composite intraseasonal oscillations of convection over southern Africa. J. Climate, 9, 1910-1920.

Liebmann, B., and C. A. Smith, 1996: Description of a complete (interpolated) outgoing longwave radiation dataset. Bull. Amer. Meteor. Soc., 77, 1275-1277.

Lindesay, J. A., 1988a: The Southern Oscillation and atmospheric circulation changes over southern Africa. Ph.D. thesis, University of the Witwatersrand, $283 \mathrm{pp}$.

_ 1988b: South African rainfall, the Southern Oscillation and a southern hemisphere semi-annual cycle. J. Climatol., 8, 1730.

_ , and C. H. Vogel, 1990: Historical evidence for Southern Oscillation-Southern African rainfall relationships. Int. J. Climatol., 10, 679-689.

Lynch, S. D., 2003: Development of a RASTER database of annual, monthly and daily rainfall for Southern Africa. WRC Rep. N 1156/1/03, 78 pp.

Lyons, S. W., 1991: Origins of convective variability over equatorial southern Africa during austral summer. J. Climate, 4, 23-39.

Madden, R. A., and P. R. Julian, 1994: Observations of the 4050-day tropical oscillation-A review. Mon. Wea. Rev., 122, 814-837.

Makarau, A., and M. R. Jury, 1997: Seasonal cycle of convective spells over Southern Africa during austral summer. Int. J. Climatol., 17, 1317-1332.

Mapande, A. T., and C. J. C. Reason, 2005: Links between rainfall variability on intraseasonal and interannual scales over western Tanzania and regional circulation and SST patterns. Meteor. Atmos. Phys., 89, 215-234.

Mason, S. J., 1995: Sea-surface temperature-South African rainfall associations, 1910-1989. Int. J. Climatol., 15, 119-135.

Matthews, A. J., 2000: Propagating mechanisms for the MaddenJulian oscillation. Quart. J. Roy. Meteor. Soc., 126, 2637-2652.

_ 2004: Intraseasonal variability over tropical Africa during northern summer. J. Climate, 17, 2427-2440. 
Mutai, C. C., and M. N. Ward, 2000: East African rainfall and the tropical circulation/convection on intraseasonal to interannual timescales. J. Climate, 13, 3915-3939.

Pohl, B., and P. Camberlin, 2006: Influence of the Madden-Julian Oscillation on East African rainfall. Part I: Intraseasonal variability and regional dependency. Quart. J. Roy. Meteor. Soc., 132, 2521-2539.

— - _ , and P. Roucou, 2005: Typology of pentad circulation anomalies over the Eastern Africa-Western Indian Ocean region, and their relationship with rainfall. Climate Res., 29, 111-127.

Rayner, N. A., D. E. Parker, E. B. Horton, C. K. Folland, L. V. Alexander, D. P. Rowell, E. C. Kent, and A. Kaplan, 2003: Global analyses of sea surface temperature, sea ice, and night marine air temperature since the late nineteenth century. J. Geophys. Res., 108, 4407, doi:10.1029/2002JD002670.

Reason, C. J. C., and H. Mulenga, 1999: Relationships between South African rainfall and SST anomalies in the South Indian ocean. Int. J. Climatol., 23, 377-393.

_ - R. J. Allan, J. A. Lindesay, and T. J. Ansell, 2000: ENSO and climatic signals across the Indian Ocean basin in the global context. Part I: Interannual composite patterns. Int. J. Climatol., 20, 1285-1327.

Richard, Y., 1994: Variabilité pluviométrique en Afrique du SudEst (in French). La Météorologie, 8, 11-22.

— S. Trzaska, P. Roucou, and M. Rouault, 2000: Modification of the Southern African rainfall variability/El Niño Southern Oscillation relationship. Climate Dyn., 16, 883-895.

Roundy, P. E., and W. M. Frank, 2004: A climatology of waves in the equatorial region. J. Atmos. Sci., 61, 2105-2132.

Streten, N. A., 1973: Some characteristics of satellite-observed bands of persistent cloudiness over the Southern Hemisphere. Mon. Wea. Rev., 101, 486-495.

Todd, M., and R. Washington, 1999: Circulation anomalies associated with tropical-temperate troughs in southern Africa and the south west Indian Ocean. Climate Dyn., 15, 937-951.

- _ — , and P. I. Palmer, 2004: Water vapour transport associated with tropical-temperate trough systems over Southern Africa and the southwest Indian Ocean. Int. J. Climatol., 24, $555-568$.
Waliser, D. E., and C. Gautier, 1993: A satellite-derived climatology of the ITCZ. J. Climate, 6, 2162-2174.

—, C. Jones, J.-K. E. Schemm, and N. E. Graham, 1999: A statistical extended-range tropical forecast model based on the slow evolution of the Madden-Julian Oscillation. J. Climate, 12, 1918-1939.

— , K. M. Lau, W. Stern, and C. Jones, 2003: Potential predictability of the Madden-Julian oscillation. Bull. Amer. Meteor. Soc., 84, 33-50.

Washington, R., and M. Todd, 1999: Tropical-temperate links in southern Africa and southwest Indian Ocean satellitederived daily rainfall. Int. J. Climatol., 19, 1601-1616.

Wheeler, M. C., and H. H. Hendon, 2004: An all-season real-time multivariate MJO index: Development of an index for monitoring and prediction. Mon. Wea. Rev., 132, 1917-1932.

Xie, P., and P. Arkin, 1997: Global precipitation: A 17-year monthly analysis based on gauge observations, satellite estimates, and numerical model outputs. Bull. Amer. Meteor. Soc., 78, 2539-2558.

— , J. E. Janowiak, P. A. Arkin, R. Adler, A. Gruber, R. Ferraro, G. J. Huffman, and S. Curtis, 2003: GPCP pentad precipitation analyses: An experimental dataset based on gauge observations and satellite estimates. J. Climate, 16, 21972214.

Xie, S.-P., H. Annamalai, F. Schott, and J. P. McCreary Jr., 2002: Structure and mechanisms of South Indian Ocean climate variability. J. Climate, 15, 864-878.

Yasunari, T., 1979: Cloudiness fluctuations associated with the Northern Hemisphere summer monsoon. J. Meteor. Soc. Japan, 57, 227-242.

— 1980: A quasi-stationary appearance of the 30-40-day period in cloudiness fluctuations during the summer monsoon over India. J. Meteor. Soc. Japan, 58, 223-229.

_- 1981: Structure of an Indian summer monsoon system with around 40-day period. J. Meteor. Soc. Japan, 59, 336-354.

Zhang, C., 2005: Madden-Julian Oscillation. Rev. Geophys., 43, RG2003, doi:10.1029/2004RG000158.

— , and M. Dong, 2004: Seasonality in the Madden-Julian oscillation. J. Climate, 17, 3169-3180. 